\title{
SER LEITOR: entre a infância e a juventude
}

\author{
Daniela Chaves Corrêa Figueiredo ${ }^{1}$
}

Míria Gomes Oliveira ${ }^{2}$

\section{RESUMO}

Nosso foco neste artigo é localizar nas práticas sociais de leitura e escrita de jovens leitores dificuldades e incentivos que impactam seus percursos leitores na passagem da infância para a juventude. O estudo foi realizado em quatro bibliotecas públicas municipais de Belo Horizonte ao longo do ano de 2014, com jovens que frequentam, escolhem, lêem livros literários e participam das atividades de leitura propostas nesses espaços. A partir das informações sobre proficiência leitora no Brasil (INAF/2012 e PISA/2012) e da perspectiva sociocultural de juventude na contemporaneidade (DAYREEL, 2003; VELHO, 2006 e PERALVA, 2007), letramento literário, comunidades leitoras e dialogismo, discutimos a formação leitora a partir dos relatos de nossos sujeitos.

Palavras-chave: Juventude. Letramento literário. Formação de leitores.

\section{SER LECTOR: ENTRE LA INFANCIA Y LA JUVENTUD}

\section{RESUMEN}

Nuestro enfoque en este artículo es demostrar en las prácticas sociales de lectura y escritura de jóvenes las dificultades e incentivos que impactan sus trayectorias lectoras en el paso de la infancia a la juventud. El estudio fue consumado en cuatro bibliotecas públicas municipales de Belo Horizonte en el año 2014, con jóvenes que frecuentan, eligen, leen libros literarios y participan de las actividades de lectura propuestas en esas instituciones. Teniendo en cuenta las informaciones sobre la competencia lectora en Brasil (INAF/2012 y PISA/2012) y la

\footnotetext{
${ }^{1}$ Mestre em Educação - Linha Educação e Linguagem (UFMG).Gerência de Monitoramento e Indicadores Culturais.

${ }^{2}$ Mestrado em Linguística Aplicada pela Universidade Estadual de Campinas e doutorado em Estudos Linguísticos pela Universidade Federal de Minas Gerais.
} 
perspectiva sociocultural de la juventud en la contemporaneidad (DAYREEL, 2003; VELHO, 2006 e PERALVA, 2007), letramento literario, comunidades de lectores y dialogismo, abordamos la formación lectora desde los relatos de nuestros sujetos.

Palabras clave: Juventud. Letramento literario. Formación de lectores.

"Quando for grande, quero ser de outra maneira. Quero ser longe. Eu respondia: ninguém é longe. As pessoas são sempre perto de alguma coisa e perto delas mesmas..."

(A Desumanização, Valter Hugo Mãe)

\section{INTRODUÇÃO}

Nosso foco, neste artigo, é localizar acontecimentos de ordem social que impactam as práticas leitoras de jovens na transição da infância para a juventude. As experiências que destacamos revelam o desinteresse por histórias para crianças, a dificuldade com os clássicos da literatura brasileira e a consciência da condição de leitor em formação. E, ainda, a importância dos espaços de leitura dialógicos presenciais ou virtuais na formação leitora de jovens. Esse estudo foi realizado em quatro bibliotecas públicas municipais de diferentes regionais da cidade de Belo Horizonte, onde encontramos jovens que as frequentam, escolhem e lêem livros de literatura e participam das atividades de leitura propostas nesses espaços. Contamos com a participação de 27 leitores, com idade entre 13 e 18 anos.

Para contextualizar o quadro de proficiência leitora do Brasil, trazemos alguns dados, destacando a população jovem. O último INAF - Indicador de alfabetismo funcional ${ }^{3}-$ revelou que, na faixa etária entre 15 e 24 anos, os níveis de alfabetismo estão divididos da seguinte forma: $0 \%$ analfabetos, $11 \%$ rudimentar $^{4}, 53 \%$ básico $^{5}$ e $36 \%$ pleno $^{6}$. Ao longo da década, o aumento em relação ao nível pleno foi de $1 \%$. O balanço feito é que, embora tenha havido a melhora desses índices, ainda assim, eles são considerados insatisfatórios,

\footnotetext{
${ }^{3}$ Refere-se à última pesquisa realizada pelo Instituto Paulo Montenegro, realizada entre 2011 e 2012.

${ }^{4}$ Localizam uma informação explícita em textos curtos e familiares.

${ }^{5}$ Leem e compreendem textos de média extensão, localizam informações mesmo com pequenas inferências.

${ }^{6}$ Leem textos mais longos, analisam e relacionam suas partes, comparam e avaliam informações, distinguem fato de opinião, realizam inferências e sínteses.
} 
principalmente em relação aos níveis mais altos de proficiência. Constata-se que o acesso dos jovens ao Ensino Médio, não tem contribuído para a qualificação desses resultados.

O Programa Internacional de Avaliação de Estudantes - PISA/20127 , iniciativa internacional de avaliação comparada, aplicada a estudantes na faixa dos 15 anos, idade em que se pressupõe o término da escolaridade básica obrigatória na maioria dos países, mostra que o nosso país avançou pouco em relação à área de leitura. Em 2000, a nossa proficiência era 396. Em 2013, atingimos 410. O que nos deixa, entre os 65 países avaliados, na $58^{\text {a }}$ posição.

Com base em Bourdieu (2008), consideramos que os fatores socioeconômicos condicionam o acesso aos bens letrados que, por sua vez, está associado à capacidade leitora da população. A pesquisa do INAF reitera essa perspectiva ao mostrar que, entre os extratos com maior renda familiar, o quantitativo de pessoas analfabetas e no nível rudimentar diminui. Além disso, o nível pleno de alfabetismo concentra-se no grupo que recebe mais de cinco salários.

Também nessa direção, Castrillón (2007) entende que a qualificação dos níveis de escrita e leitura da população está associada ao desenvolvimento humano e à diminuição das desigualdades socioeconômicas e culturais. A autora parte do pressuposto de que o acesso à cultura escrita é um direito dos cidadãos, que requer responsabilidades compartilhadas. Nas palavras da autora: "El problema de la lectura sólo puede ser "encarado y resuelto" mediante cambios dirigidos a una distribución de la riqueza más justa y equitativa y una mayor inversión en educación" (p.2).

Quando tratamos da formação leitora, é recorrente entre os educadores o discurso de pouco interesse da juventude em relação à leitura, principalmente, a literária. Em nosso estudo foi possível identificar obstáculos, dificuldades, posturas, incentivos e descobertas, relacionados às dimensões econômicas, culturais e subjetivas, que transformam as práticas leitoras dos jovens.

Os nossos leitores relatam que a diversificação dos interesses culturais, a ampliação das atividades não-escolares e o fascínio pelas tecnologias digitais diminuem o tempo para leitura. Porém, os indicadores apresentados oferecem-nos dados e indícios para a discussão em torno da transição nos processos de formação do feitor jovem, que extrapolam esses

\footnotetext{
${ }^{7}$ Resultados disponíveis em: <http://portal.inep.gov.br/internacional-novo-pisa-resultados〉.
} 
apontamentos. Vemos que a maior concentração da proficiência leitora está no nível básico e que o encontro com textos mais complexos na juventude requer a mediação de leitores experientes, pois os jovens têm dificuldades para compreendê-los, como veremos em nossos dados.

Destacamos que, mesmo em um grupo de jovens interessados em literatura e bibliotecas públicas, há interditos em suas práticas leitoras na transição da infância para a juventude. Essa constatação indica a relevância da análise dessas práticas para melhor compreendermos a formação leitora.

Em nossa abordagem teórica assumimos a noção de juventude como construção da contemporaneidade que ao longo da história foi sendo ressignificada. A partir da perspectiva sociocultural apresentamos nosso entendimento sobre práticas de leitura e concepção de leitor, fundamentado nos conceitos de dialogismo, letramento literário e comunidade de leitores. Com base nesses pressupostos, discutimos a formação leitora a partir dos relatos de nossos jovens focando em fatores de ordem social e subjetiva que impactam as escolhas de textos literários.

\section{A COMPREENSÃO CONTEMPORÂNEA DE JUVENTUDE}

A compreensão das práticas culturais exercidas pelos jovens provoca a reflexão em torno da noção contemporânea de juventude. Entendemos essa categoria como construção sociocultural das sociedades modernas, que passa constantemente por releituras, conformadas por diferentes realidades sociais, culturais e econômicas. Como explica Peralva (2007, p.13): "as idades da vida embora ancoradas no desenvolvimento biopsíquico dos indivíduos, não são fenômeno puramente natural, mas social e histórico, datado, portanto, e inseparável do lento processo de constituição da modernidade". Também nessa direção, Velho (2006) aponta que as denominações etário-geracionais são estabelecidas com base nos diferentes modos de negociação da realidade, através dos processos de interação social, influenciados por fatores econômicos, sociais, políticos e simbólicos.

Essa concepção de juventude, que extrapola os aspectos cronológicos, psicológicos e biológicos, parece-nos mais adequada à compreensão de práticas culturais de leitura e escrita 
tomadas na relação entre o meio social e as experiências do jovem-leitor. Se, por um lado os dados estatísticos são importantes para a avaliação das políticas públicas de leitura, por outro lado, as experiências singulares dos nossos jovens, possibilitam ao formador de leitores entender para melhor mediar a leitura literária.

Também a noção de juventude é forjada por aspectos sociais, culturais, econômicos e pela manifestação da subjetividade dos jovens em suas práticas culturais, deixando ver a multiplicidade e parcialidade das representações já que essa fase da vida não é vivenciada de forma homogênea (FROTA, 2007). Como explica Viana (2014, p. 251):

[...] a cultura é um campo vasto mais amplo e diz respeito a um conjunto de elementos materiais e simbólicos historicamente construídos que conferem identidade a um determinado grupo social ou sociedade. Nessa visão, não existe uma cultura única, universal, hegemônica. Ao contrário, pensamos na perspectiva de culturas, no plural, com vistas a contemplar e defender as especificidades e a diversidade de experiências vividas por grupos e indivíduos.

Portanto, entendemos que as práticas leitoras dos nossos jovens são influenciadas por fatores socioeconômicos relacionados ao acesso dos bens letrados que não apagam as singularidades de cada sujeito diante da experiência. Nessa direção, Dayrell (2003) considera que há diferentes possibilidades de apropriação do social, de forma a romper com a ditadura do consumo, nas quais se percebe um alargamento dos interesses e práticas coletivas juvenis, especialmente, na dimensão cultural. Essas, por sua vez, proporcionam formas singulares de sociabilidade, experiências coletivas e de interesses comuns.

Consideramos, também, que as subjetividades são forjadas por princípios internos (disposicionais) e externos (contextuais), que estão recorrentemente em contradição ao longo de nossas vidas, desde o nascimento. As subjetividades são constituídas e ampliadas em diferentes contextos por meio das interações sociais. Lahire (2004) explica que o rompimento com a noção de singularidade dissociada das questões socioculturais constitui-se em avanço na produção do conhecimento. Isto é, o limiar entre ser constituído e constituir-se é bastante tênue, pois acontece no contato dialógico com diferentes discursos.

Dessa forma, assumimos a leitura literária como prática sociocultural que envolve a discussão sobre dialogismo discursivo, letramento literário, comunidade de leitores e a concepção de leitor, como discutimos a seguir. 


\section{LEITURA LITERÁRIA: SINGULARIDADES DE UMA PRÁTICA SOCIOCULTURAL}

O arcabouço teórico em torno da atividade leitora é constantemente ressignificado. Para além das concepções bottom-up ou top-down, compreendemos essas práticas a partir da perspectiva discursiva, em que leitores e autores são igualmente produtores de sentidos em um processo dialógico. Ou seja, como espaços nos quais leitores e textos interagem, abrindose para novos discursos ou para a reelaboração dos velhos, contestando verdades prontas e acabadas.

Rojo (2004) assinala que a concepção focada, sobretudo, nas capacidades de decodificação e na fluência leitora, possibilitou o entendimento de leitura como um ato de cognição e de compreensão textual, em que para se captar os propósitos e significações do texto, o leitor precisava convocar saberes em torno de práticas e normas sociais. Em relação à perspectiva discursiva, considera que a leitura coloca o texto (discurso) em confronto com outros discursos presentes nas sociedades, que se enredam:

[...] o discurso/texto é visto como um conjunto de sentidos e apreciações de valor das pessoas e coisas do mundo, dependentes do lugar social do autor e do leitor e da situação de interação entre eles - finalidades de leitura e da produção do texto, esfera social de comunicação em que o ato da leitura se dá (p.3).

$\mathrm{O}$ entendimento da leitura como prática sociocultural leva-nos também à discussão sobre letramento literário que extrapola o domínio das capacidades de decifração do código escrito associado à participação ativa no cotidiano letrado. Demanda, sobretudo, o envolvimento e a experimentação sistemática e intensa dos textos nas suas várias formas de expressão.

Para Paulino (2004, p.56), o letramento literário está associado à experimentação de produções escritas de caráter artístico, em que se reconheçam:

"marcas linguísticas de subjetividade, intertextualidade, interdiscursividade, recuperando a criação de linguagem realizada, em aspectos fonológicos, 
sintáticos, semânticos, situando adequadamente o texto em seu momento histórico de produção".

Dessa forma, um sujeito literariamente letrado é aquele que percebe a construção estética da língua, aceita o pacto ficcional e a recepção não-pragmática da obra, bem como utiliza estratégias de leitura apropriadas aos textos literários. São leitores que tomam a leitura literária como parte do cotidiano, constituída, especialmente, como prática sociocultural, dissociada de funções utilitárias, interagindo com texto de forma subjetiva. Diríamos que, um leitor é literariamente letrado quando se envolve em textos literários de diferentes formas e conteúdos. De pequenos contos, a romances épicos extensos. De haicais aos diferentes sonetos e poemas de versos livres.

O letramento literário, bem como outros tipos de letramento, continua sendo uma inserção pessoal em práticas socioculturais de leitura e escrita, perpassando por diferentes instâncias (PAULINO, 2004, 2007).

$\mathrm{Na}$ concepção discursiva de leitura as regras são construídas e compartilhadas nas/pelas comunidades de leitores que constroem e reproduzem sentidos. Ou seja, o texto não é "receptáculo fiel do sentido", o controle da leitura está submetido aos sujeitos, que estão imersos em determinados contextos sócio-históricos, responsáveis pelas "condições de produção" (CORACINI, 1995, p.16). Segundo a autora, a interpretação está sempre em construção, pois resulta da localização do leitor em certo momento e lugar:

[...] não é o texto que determina as leituras [...] mas, o sujeito, não na acepção idealista de indivíduo, uno, coerente, porque dotado de razão, como queria Descartes, graças a qual lhe é possível controlar conscientemente a linguagem e o sentido, mas enquanto participante de uma determinada formação discursiva, sujeito clivado, heterogêneo, perpassado pelo inconsciente, no qual se insere o discurso (p.18).

Nessa concepção, o ato leitor, que requer compreensão, interpretação e produção de sentidos pelos sujeitos, também está associado ao ponto de vista, à percepção e ao lugar de enunciação.

Para Barros (2003, p.2), na visão discursiva, a construção de sentido do discurso acontece por meio de uma interação dialógica entre "o enunciador e o enunciatário, no espaço do texto", denominada de dialogismo discursivo. Nele, dois aspectos se distinguem: "o da interação verbal entre o enunciador e o enunciatário do texto e o da intertextualidade no 
interior do discurso". Em outras palavras, nesse conceito inclui-se o espaço interacional entre o eu (leitor) e o tu (outros presentes no texto).

A compreensão dos nossos jovens em relação à leitura literária oscila entre o caráter utilitário, que visa ao atendimento de demandas cotidianas das sociedades letradas (ampliação de vocabulário de acordo com as instituições em que circula, uso da norma padrão escrita e oral) e o de aceitação do pacto ficcional e de interação subjetiva com as obras.

Em nossos dados, notamos essa oscilação nos depoimentos seguintes:

Karina: ...O último livro que eu li: "A dança da floresta", no momento que a personagem sentia frio eu conseguia sentir o frio, eu evolvia mesmo. Eu me sentia como a personagem..." (Leitora/BBA - 14 anos, entrevista, 2014, grifos nossos).

Inês: ...Porque o livro ajuda você a falar melhor, você conviver com as pessoas, acho assim muito importante mesmo pra você estar no seu local de trabalho. Porque a literatura além, de ajudar você a ler, ela ajuda a entender as palavras... (Leitora/BBA - 17 anos, entrevista, 2014, grifos nossos).

Karina aceita o pacto ficcional, identifica-se com a personagem a ponto de reproduzir suas sensações: “...no momento que a personagem sentia frio eu conseguia sentir o frio[...]Eu me sentia como a personagem... ’. Para Butlen (2012) essa adesão ao texto é fundamental para a formação inicial do leitor, entretanto o autor considera a necessidade de ampliação dessa perspectiva, cujo distanciamento dos textos e diálogo com os repertórios leitores estabelecidos sejam explorados, para que a leitura torne-se “...experiência singular, uma prática cultural que gera troca entre os leitores, confrontos, sociabilidade, uma postura crítica..." (p.38).

Inês acredita que a leitura influencia sua postura profissional e contribui para a melhor compreensão do vocabulário, não desconsideramos essas possibilidades, porém, como Rojo (2004, p.1), entendemos que "ser letrado é ler na vida e na cidadania", significa ir além da literalidade dos textos, é preciso compreendê-los, interpretá-los, estabelecendo relações com outros textos e discursos, situando-os no contexto social. Isto é, dialogar com os textos, analisando os diferentes posicionamentos e ideologias que conformam seus sentidos. É trazêlos para o cotidiano e colocá-los em relação com a vida.

É na ampliação e qualificação dos modos de interação com os textos que entendemos a importância das propostas de mediação com vistas à formação de leitores críticos. O letramento literário requer experiências dialógicas promovidas nos espaços de leitura, em que 
se deixe ouvir as diferentes vozes do discurso, cujas identidades são desestabilizadas e as verdades contestadas (AUTOR, 2005).

Assumir as práticas leitoras como espaços de interação social leva-nos ainda à ideia de comunidades de leitores, que para Pinheiro (2008, p.112) são forjadas por "comportamentos, saberes, atitudes, valores autorizados, uniformizados" entre seus participantes. Isto é, nelas são disseminados diversos modos de produção de sentidos, assim como "conceitos e valores" que orientam as experiências dos sujeitos com os textos nos contextos socioculturais aos quais pertencem.

Consideramos que as singularidades da apreensão leitora ou a construção de saberes literários não são estritamente da ordem do particular, nem só da ordem do coletivo. Isto é, os sujeitos estão imersos em formações discursivas nas quais se constituem ao mesmo tempo em que contribuem para deslocamentos de sentidos nas interações cotidianas. Dito de outra forma: a singularidade é uma construção social, que está associada também ao contexto histórico e à interação com o outro, em que o leitor não se apaga diante do que lhe é trazido pelo texto literário.

Assim como a leitura, a ideia que se tem de leitor é provisória. Ambas as concepções são forjadas por contextos sócio-históricos. Se as subjetividades são de natureza social, a identidade leitora é interpelada por diferentes eventos sociais e pelo contato com variados discursos. Os sujeitos ora aceitam, ora resistem a esse outro revelado especialmente nos textos literários (AUTOR, 2008).

Assumimos a concepção crítica de leitor que inclui a dimensão política do que seja ser um sujeito letrado em nossa sociedade, como aquele que é capaz de ouvir, diferenciar e compreender vozes dissonantes presentes nos discursos. Ou seja, que perceba essa pluralidade como aspecto seminal das democracias, nas quais a visão unilateral de sociedade perfeita é desestabilizada (AUTOR, 2014). Nessa perspectiva, o leitor dialogicamente produz e negocia sentidos, reelabora saberes, questiona valores veiculados a partir do próprio contexto para produzir conhecimentos significativos (AUTOR, 2000, p.36). Percebe ainda que essas interações permitem a interlocução entre discursos de diferentes contextos, nos quais as desigualdades socioeconômicas são vistas.

Como base nos conceitos apresentados, discutimos a formação leitora e retomamos os discursos sobre juventude e práticas de leitura literária nas escolas. 


\section{FORMAÇÃO LEITORA DE JOVENS: TEMPOS E ESPAÇOS}

Vimos discutindo que as práticas socioculturais são modificadas e ressignificadas ao longo do tempo. A contemporaneidade apresenta-nos experiências de formação leitora que nos escapam em complexidade, mas que provocam reflexões, levando-nos a indagações éticas e estéticas. Os modos de interação e os suportes textuais foram ampliados para além do espaço escolar e familiar, transformados especialmente pelas interações tecnológicas em telas, que marcam a terceira era da escrita. Por isso, não podemos falar de leitores jovens sem falar de tecnologias da escrita na era digital ou, como propõe Canclini (2008), fazer associações leitor - expectador - internauta.

Leyva (2012, p.192) assinala que a tecnologia digital representa uma mutação geracional da contemporaneidade. Em relação às práticas de leitura, a autora considera que os núcleos leitores deixam de ler locais para se tornarem mundiais. E, forjados na textualidade eletrônica, passam a ter uma estrutura flexível e cambiante. Em nosso entendimento, a textualidade eletrônica é gerada em práticas econômicas e culturais globais. Segundo a autora, esses modos de interação que misturam a comunicação oral, visual e escrita no formato hipertextual criam novas formas de convivência e sociabilidade.

Nesse contexto, observamos que a juventude passa a estabelecer novas redes de interação, ampliando suas práticas culturais através da leitura em telas. Consequentemente, esse movimento modifica os modos de ler, fazendo com que esses sujeitos tenham experiências leitoras autônomas, nem sempre esperadas ou realizadas na escola. O depoimento seguinte mostra essa dinâmica na percepção de Letícia sobre a literatura:

Letícia: “...literatura, eu penso no que eu tô estudando no colégio, que é o que a literatura desenvolveu e tal, de poemas, no barroco, "blá, blá, blá". Isso assim da literatura não me interessa, me interessa o atual /.../ a literatura com os livros que eu leio..." (Leitora/BCS - 14 anos, entrevista, 2014, grifos nossos).

Nesse fragmento, o papel ativo de Letícia em suas experiências leitoras é reconhecido quando a leitora expressa que literatura são os livros lidos por ela: “...me interessa o atual /.../ a literatura com os livros que eu leio...”. Esses novos modos de interação com os textos 
incluem a ambiguidade de relacionamento com as estruturas dominantes, ora resistindo, ora se sujeitando (REGUILLO, 2007, p.57).

O depoimento de Letícia sinaliza também que seu letramento literário escolar continua voltado para o estudo dos estilos de época, da sintaxe e da leitura de excertos de textos literários, presentes nos livros didáticos, aspectos que, muitas vezes, levam os jovens a dissociarem a leitura literária das práticas escolares.

Pensar a formação leitora como ação transformadora requer o letramento literário, devido ao conhecimento que guarda e ao seu valor simbólico no mundo da escrita. Consideramos que uma sociedade multifacetada como a nossa demanda o exercício de práticas significativas, que permitam a produção de conhecimentos e experiências, com vistas ao posicionamento autônomo dos sujeitos frente a essa complexa realidade (CRUVINEL, 2011). Destacar a literatura na formação leitora de jovens é entendê-la como um direito do cidadão em tempos de globalização do capital. Esse posicionamento reitera nosso entendimento de que ser leitor ultrapassa o sentido funcional de educação para o mercado de trabalho.

As leituras literárias têm peculiaridades, é uma atividade interpretativa e produtora de sentidos. Através delas, reconstroi-se a perspectiva histórica das sociedades, que resgatam nossa identidade (BRITTO, 2012). Favorece-se a ampliação da capacidade interpretativa crítica dos indivíduos, que consideramos princípio fundamental da formação cultural ampla (OURIQUE, 2009). Essa prática constitui-se como leitura de fôlego ou extensiva, que se destaca entre outras formas.

Para Autor (2008, p.106): “as discussões sobre sujeito parecem estar sempre junto às preocupações éticas já que a formação da subjetividade se dá através de suas relações com o outro". A dimensão ética, que compreende nossa relação com o outro, cuja diversidade é mostrada, também se revela nas leituras literárias. Esse movimento dialógico permite conhecer a nós mesmos.

Ainda que o nosso foco esteja voltado principalmente para a leitura literária, entendendo que a formação leitora envolve a experimentação de diferentes gêneros textuais, localizamos esse interesse nos relatos de nossos jovens, colaborando para a expansão de seus repertórios leitores. Veloso (2003, p.161) considera que os textos informativos possibilitam a 
satisfação da curiosidade dos leitores, assim como a ampliação da capacidade cognitiva, possibilitando a compreensão de que "o livro é uma fonte de conhecimento do mundo".

Ao pensar a formação leitora como educadores, tendo a liberdade e o dever como premissas, nossos esforços concentram-se em destacar as vozes do conhecimento selecionado, procurando garantir a expressão das múltiplas consciências que emergem desses discursos para que o diálogo aconteça, contribuindo para o desenvolvimento da postura "críticointeracional".

É a partir desses pressupostos teóricos que passamos a discutir questões pertinentes à trajetória leitora de nossos leitores na transição da infância para a juventude.

\section{SER LEITOR: ENTRE A INFÂNCIA E A JUVENTUDE}

Nosso discussão sobre ser leitor entre a infância e a juventude busca identificar nas práticas de leitura e escrita acontecimentos de caráter social - obstáculos, dificuldades, posturas, mudanças, comportamentos e descobertas - que impactam seus percursos como leitores. Os participantes da pesquisa são frequentadores de bibliotecas públicas de Belo Horizonte situadas na região do Barreiro (BBA), Centro-Sul (BCS), Nordeste (BNE) e Venda Nova $(\mathrm{CCVN})$ e estudam em escolas públicas e particulares do Ensino Fundamental e Médio, exceto uma leitora que cursa Pedagogia. Eles pertencem a diferentes meios sociais e possuem condições socioeconômicas distintas. Seguimos contextualizando essa discussão nas vozes de nossos leitores.

\section{Primeiro acontecimento: as leituras da infância não servem mais}

Identificamos dois movimentos distintos na trajetória dos nossos leitores, jovens que interromperam suas leituras literárias e outros que iniciaram essas práticas na juventude. $\mathrm{O}$ depoimento seguinte evidencia o primeiro deslocamento.

Roger: ...quando era criança eu lia pra caramba /.../ depois que eu parei de gostar de ler /.../ eu tava indo pra escola /.../ passei na casa de uma menina que tinha um livro da série que eu gostava e eu comecei a ler.

P: E que livro que era? Você pode falar?

Roger: "The walking dead"... 
P: E o que você pensa: "Ah, eu lia muito na infância e eu parei de ler na adolescência. A que você atribui isso? /.../Tem algum motivo especial?

Roger: Eu saía, nada me interessava, já livro de terror me interessa. (Leitor/BBA - 14 anos, entrevista, 2014, grifos nossos).

O depoimento mostra o afastamento de Roger das leituras literárias entre a infância e a adolescência nos fragmentos "...quando era criança eu lia pra caramba /.../ depois que eu parei de gostar de ler...”. A afirmação “Eu saia, nada me interessava...” mostra a falta de interesse por leitura durante este período da vida de Roger. No entanto, um acontecimento casual desperta novamente sua motivação: a leitura de literatura de terror realizada por um colega. Roger redescobre o gosto e faz sua escolha de leitura por um título que circula em seu meio social, motivando-o : “...passei na casa de uma menina que tinha um livro da série que eu gostava e eu comecei a ler. É por meio da interação social com sua colega que o leitor recomeça suas leituras. Dessa forma, a influência da família e da escola, tão marcada nos relatos de práticas de leituras na infância, é realizada por seus pares em situações sociais aleatórias. A leitura em comum marca a busca por emancipação, tão característica à juventude, trazendo sentimento de pertencimento a sua própria comunidade de leitores.

É importante notar que o mercado editorial no Brasil aposta no gênero "literatura de terror" para leitores entre a infância e a juventude. Assim, se por um lado o leitor se aventura em práticas autônomas, não prescritas por instituições socialmente legitimadas para formar leitores, por outro lado, o mercado conforma o leitor jovem às publicações pré-direcionadas a esse público, em sua maioria best sellers estrangeiros. No nosso entendimento, a literatura de entretenimento aproxima os jovens dos livros, mas não forma leitores críticos como defendemos.

\section{Segundo acontecimento: a consciência da condição de leitor em formação}

Entre os depoimentos de nossos sujeitos, notamos que o respeito a suas preferências leitoras no processo de formação do jovem leitor é considerada importante. Todavia, eles também se mostram abertos a novas propostas, como evidencia a postura de Renato no próximo relato.

Renato: ... a pessoa tem que levar em consideração se eu gosto, se não conhecer muito sobre o que a pessoa gosta até não vejo muito problema, a não ser que queira é... ampliar o gosto da pessoa. 
P: ...Cê tá falando /.../ em não considerar o que você gosta (como) possibilidade de ampliação /.../ Essa prática cê acha que é positiva, negativa...

Renato: Eu acho que é positiva sim, porque quando a gente lê amplia os conhecimentos, cê vai lendo mais "gênero", vai interessando por mais "tipo" de livros, vai ampliando cada vez mais, é... conhecimentos literários... escrita entre outras coisas (Leitor/BVN - 16 anos, entrevista, 2014, grifos nossos).

Inicialmente, Renato reitera a necessidade de consideração dos seus gostos literários: “... a pessoa tem que levar em consideração se eu gosto...”, depois sinaliza a percepção da sua condição de leitor em formação que requer a intervenção de mediadores mais experientes: “...a não ser que queira é... ampliar o gosto da pessoa...”. Essa abertura ao desconhecido mostra a importância da dimensão dialógica para a formação crítica do leitor ao colocá-lo em contato com outras vozes do discurso: “...cê vai lendo mais "gênero”, vai interessando por mais "tipo" de livros, vai ampliando cada vez mais, é... conhecimentos literários...".

Compreender o valor da literatura na própria vida e ter consciência da condição de leitor em formação são aspectos que dialogam com a concepção de leitor crítico que defendemos. Nessa perspectiva os jovens assumem as práticas leitoras como possibilidade de transformação pela ampliação do conhecimento de mundo.

\section{Terceiro acontecimento: a dificuldade em ler os clássicos}

A dificuldade em ler os clássicos da literatura brasileira foi recorrente entre nossos leitores, por isso a rejeição dessas obras. Destacamos o depoimento de Alícia.

P: ...Porque você acha que os jovens não gostam desses livros /.../?

Alícia: Porque muitas vezes eles não entendiam, às vezes, nem eu mesmo entendia. Quando você vai plantar uma sementinha tem que ter o tempo pra você plantar, não tem? Tem que ter o terreno já preparado, às vezes, não tava na hora, no momento deles lerem aquele tipo de livro. Talvez, ia ser mais pra frente /.../ não tinha maturidade suficiente..." (Leitora/BCS - 17 anos, entrevista, 2014, grifos nossos).

Para a leitora o obstáculo na leitura desses textos refere-se à dificuldade de compreensão: “...Porque muitas vezes eles não entendiam, às vezes, nem eu mesmo entendia...”. Logo a seguir, Alícia traz a metáfora da semente para definir sua concepção de 
formação leitora como um processo gradual e contínuo: “...Quando você vai plantar uma sementinha /.../ Tem que ter o terreno já preparado...”. Ora, se tomamos a leitura literária como prática discursiva, como estabelecer o pacto ficcional se a linguagem não permite a interação entre leitor e texto? Como produzir e negociar sentidos sem compreender o que se lê?

Não se pode esperar que a juventude entre no Ensino Médio e comece a ler os clássicos da literatura brasileira sem a mediação dos educadores, principalmente quando as pesquisas apontam que 64\% dos jovens estão nos níveis de proficiência leitora rudimentar e básica. A leitura dessas obras, devido à distância do universo sociolinguístico dos nossos leitores, requer mediações que situem os contextos de produção dessas obras (político e histórico), confrontando aspectos de linguagem, vocabulário e estilo. O modo como a escola tem conduzido essas práticas, ao contrário de formar o leitor, parece deformá-los, como bem expressa Alícia: “...Na escola, às vezes, falam pra você ler /.../ o adolescente não entende nada daquele Machado de Assis e acaba tomando raiva de ler...".

Essa dificuldade com os clássicos que desestabiliza a trajetória leitora dos jovens: “...o adolescente /.../ acaba tomando raiva de ler...", requer a intervenção dos formadores de leitores para superação dessa dificuldade. A qualificação das escolhas textuais requer incentivo e acesso a diferentes gêneros, pois são fundamentais para a formação leitora crítica.

Essa rejeição inicial dos clássicos da literatura brasileira convoca-nos a repensar nossas práticas de mediação, pois essas obras são marcadas por antagonismos de diferentes grupos sociais, abordam relações étnico-raciais e de gênero que, embora estejam longe no tempo, estão próximas das histórias de vida dos nossos leitores. A aproximação desses universos, relacionando-os com outros discursos presentes na sociedade, é necessária para a construção e negociação de sentidos entre os jovens.

\section{Quarto acontecimento: as experiências leitoras dialógicas}

Assumimos a leitura como uma prática sociocultural em que o compartilhamento de sentidos entre sujeitos de uma mesma comunidade leitora contribui para a construção de leitores críticos. Nosso estudo revela que as práticas de leitura escolares cujas trocas são incentivadas promovem a aproximação entre leitor e texto: 
P: Vamos pegar lá o exemplo do rodízio que você falou. Fala um pouquinho como funciona isso, o que você acha, a sua opinião sobre a prática.

Daniel: ...o colégio estabelece esse rodízio pra poder incentivar os jovens a ler /.../ A gente vai descobrindo novos livros, livros que a gente nunca ouviu falar, vários livros antigos de autores que a gente nem conhece, vai descobrindo e vai adorando, sabe? Quando eu vivenciei esse momento no quinto ano, eu achei chato /.../ Então, teve a segunda etapa /.../ e eu fui começando a gostar /.../ Eu acho uma boa prática, em todas as escolas devia ter, sabe?... (Leitor/BNE - 13 anos, entrevista, 2014, grifos nossos).

Para Daniel, o rodízio é considerado boa prática, porque além de incentivar a leitura entre os jovens, também, possibilita o conhecimento de livros que extrapolam suas preferências: “...A gente vai descobrindo novos livros /.../ livros antigos de autores que a gente nem conhece...”. Na medida em que a escola favorece a expansão dos repertórios, os leitores se formam em um processo coletivo, como expressa o leitor: "...Quando eu vivenciei esse momento no quinto ano, eu achei chato /.../ Então, teve a segunda etapa /.../ e eu fui começando a gostar...”, Percebe-se também que o rodízio provoca mudanças de comportamentos na medida em que o leitor vai se inserindo na comunidade: “...teve a segunda etapa /... e eu fui começando a gostar...”.

Se compreendermos a literatura como direito, parte do cotidiano de nossos jovens, a promoção de práticas de leitura com espaço para o compartilhamento de ideias, opiniões e impressões sobre os textos é essencial para o letramento literário crítico, nas quais os leitores são produtores de sentidos negociados nas comunidades leitoras. Consideramos ainda que a seleção criteriosa das obras e a mediação dialógica provocam o questionamento de valores, a ressignificação de conhecimentos e os deslocamentos identitários.

\section{Quinto acontecimento: a internet conecta leitores}

$\mathrm{Na}$ contemporaneidade, os meios digitais criam diferentes linguagens, que geram novas formas de sociabilidade do texto literário. A internet possibilita que o compartilhamento de leituras ocorra virtualmente e nos suportes e dispositivos gerados pelas redes sociais. 
Bruna: "...Tem até um site na internet, eu acho que chama: "Esculb, Escalub" $\left(\right.$ Skoob $\left.^{8}\right)$ /.../ você posta os livros que você leu, dá resenha dos livros, pode trocar com outras pessoas na internet esses seus livros. Eu até tenho, coloco os livros que eu já li, escrevo sobre eles, os que eu mais gostei, os que eu não gostei...” (Leitora/BNE - 18 anos, entrevista, 2014, grifos nossos).

Esses modos de interação social possibilitam a formação de comunidades leitoras virtuais, nas quais os leitores trocam impressões sobre os livros: “...você posta os livros que você leu, dá resenha dos livros, pode trocar com outras pessoas. As considerações escritas favorecerem a troca de sentidos e compreensões sobre as narrativas. Esses espaços virtuais permitem que os jovens exponham suas opiniões sobre os textos: “...escrevo sobre [os livros], os que eu mais gostei, os que eu não gostei...”, mostrando também a dimensão crítica dessa prática ao abrir possibilidades de interações dialógicas já que a compreensão de um leitor passa pelo crivo de outros leitores possibilitando que diferentes posicionamentos sobre discursos variados sejam debatidos.

Ainda que os espaços virtuais estejam ocupados pelo mercado editorial, influenciando as escolhas textuais dos nossos jovens, as interações nessas redes produzem novas inteligibilidades. A apropriação crítica dessas práticas e suas ferramentas pode oferecer subsídios para a qualificação das mediações de leitura propostas por educadores, inclusive em relação aos clássicos da literatura brasileira.

Logo, não substituem as práticas leitoras promovidas nas instituições formais de educação, como bem expressa Giovana: “...Na escola, eles procuram fazer mais essas coisas pra entender [o que está] por trás do livro e o significado do livro, eles discutem mais profundo (Leitora/BCS - 15 anos, entrevista, 2014). Construir o entendimento de que as práticas leitoras têm diferentes finalidades é parte do letramento literário dos nossos jovens.

\section{CONSIDERAÇÕES FINAIS}

Nossa reflexão procurou mostrar situações cotidianas vivenciadas por jovens leitores que desestabilizam as práticas de leitura, como no caso de Roger, cuja falta de novos repertórios é obstáculo para a continuidade de sua formação leitora.

\footnotetext{
8 <www.skoob.com.br>
} 
A consciência da condição de leitor em formação é fator importante para a ampliação do repertório leitor, como visto no depoimento de Renato. Ele aceita a indicação de livros fora de seu repertório com vistas à expansão de seus conhecimentos literários. Estar aberto a leituras diversas é uma atitude importante para o letramento literário.

O depoimento de Alícia mostra a dificuldade encontrada na leitura de clássicos da literatura brasileira em contexto escolar. A metáfora da semente, contada sensivelmente por Alícia, contribui para o entendimento do processo de formação de leitores. E o depoimento de Daniel deixa ver que as práticas escolares dialógicas promovem a ampliação dos repertórios leitores e dos conhecimentos literários, aspectos importantes para formar leitores críticos.

Tomamos o relato de Bruna como exemplo para destacar as descobertas de espaços que modificam os modos de interação com os textos, por exemplo, as redes sociais de leitores. Sites que favorecem a partilha de impressões e opiniões sobre as narrativas, criando comunidades leitoras digitais, são uma opção para a expansão do repertório e para práticas de leitura e escrita literárias coletivas.

Ao longo de nosso debate, fizemos provocações. Se na contemporaneidade os espaços de educação foram ampliados por suportes virtuais, qual o papel dos educadores na mediação da leitura literária? As novas formas de sociabilidade desestabilizam os conhecimentos acerca da formação leitora. As atividades de promoção da leitura também requerem transformações. Como conciliar de forma ética discursos que vêm de diferentes contextos socioculturais? Atuar nessa perspectiva convoca nosso "desejo de desaprender o que já não nos serve e municiar-nos de discursos que incitam a agir eticamente e a nos transformar (FISCHER, 2011, p.55).

A interlocução com as práticas culturais e o conhecimento das variadas ferramentas que produzem educação na contemporaneidade para além do ensino formal são fundamentais. Em relação às práticas de leitura, talvez o maior esforço seja - educadores e jovens compreenderem o seu valor nas sociedades letradas. Isto é, sua função social relacionada ao pleno exercício da cidadania e ao desenvolvimento da postura crítica frente às contradições que se apresentam a todo o momento de nossas vidas. 
Nesse sentido, nossas reflexões podem contribuir para a qualificação do debate teórico-metodológico sobre a formação do leitor literário e, ainda, mobilizar os educadores a se aproximarem das práticas leitoras dos jovens fora dos muros escolares.

\section{REFERÊNCIAS}

BARROS, Diana Luz Pessoa de. Dialogismo, polifonia e enunciação. In: Dialogismo, polifonia, intertextualidade: em torno de Bakhtin. São Paulo: Editora da Universidade de São Paulo, 2003. p. 1-9.

BOURDIEU, Pierre. Os três estados do capital cultural. In: NOGUEIRA, Maria Alice Nogueira; CATANI, Afrânio (orgs.). Escritos da educação. Petrópolis, RJ: Vozes, 2008, p.7279.

BRITTO, Luiz Percival Leme. Inquietudes e desacordos: a leitura além do óbvio. Mercado de Letras, 2012.

CASTRILLÓN, Sílvia. Organización de la sociedad civil por el derecho a leer ya escribir. 2007. Disponível em:

<http://www.cerlalc.org/redplanes/secciones/Documentos/Castrillon_Organizacion_sociedad_ civil.pdf > Acesso em 22 de out. de 2013.

CORACINI, Maria José Rodrigues (org). O jogo discursivo na aula de leitura. Campinas, SP: Pontes, 1995. p. 13-19.

CRUVINEL, Maria de Fátima. Leitura literária na escola e construção de subjetividades. IV EDIPE: Encontro Estadual de Didática e Prática de Ensino, 2011. Disponível em: http://www.ceped.ueg.br/anais/ivedipe/pdfs/lingua_portuguesa/co/222-478-1-SM.pdf. DAYRELL, Juarez. O jovem como sujeito social. Rev. Bras. Educ., Dez 2003, nº.24, p.4052. Disponível em: http://www.scielo.br/pdf/rbedu/n24/n24a04.pdf. Acesso em: 24 de julho de 2015.

DIOS, Cyana Leahy. A educação literária de jovens leitores: motivos e desmotivos. In: RETTENMAIER, Miguel; RÖSING, Tania M. K. (orgs.). Questões de literatura para jovens. Passo Fundo: Ed. da Universidade de Passo Fundo, 2005. p.33-40.

Disponível em: $<$ http://www.oecd.org/pisa/ $>$. Acesso em: 12 de set. 2017.

Disponível em: <http://acaoeducativa.org.br/wp-content/uploads/2011/10/informe-deresultados inaf2011.pdf>. Acesso em: 12 de set. 2017.

FISCHER, Rosa Maria Bueno. No jogo da vida, experiências e narrativas de si e com o outro. In: MARTINS, Aracy Alves [et al.] (orgs.). Livros e telas. Belo Horizonte: Editora UFMG, 2011. p. 46 a 57. 
FROTA, Ana Maria Monte Coelho. Diferentes concepções da infância e adolescência: a importância da historicidade para sua construção. Estudos e Pesquisas em Psicologia, UERJ, Rio de Janeiro, v. 7, n. 1, p. 147-160, abr. 2007. Disponível em <http://www.revispsi.uerj.br/v7n1/artigos/pdf/v7n1a13.pdf> Acesso em 06 Jan. de 2012.

LAHIRE, Bernard. Bernard. Retratos sociológicos: disposições e variações individuais. Porto Alegre: Artmed, 2004.

LEYVA, Elsa Margarita Ramírez. La instituición bibliotecária: uma fuerza fundamental para los jóvenes lectores del siglo XXI. In: PÉREZ, Leticia Rodríguez. Leer en siglo XXI. Cuba: Editorial Gente Nueva, 2012. p. 187-201.

OURIQUE, João Luís Pereira. Aspectos culturais e impasses conservadores: a literatura entre o ensino e a formação. In: Caderno de Letras / Faculdade de Letras. Universidade Federal de Pelotas. Ensino de línguas e literatura: críticas e metodologias, Pelotas, 2009, n.15, p. 13 25.

PAULINO, Graça. Formação de leitores: a questão dos cânones literários. Portugal: Revista Portuguesa de Educação,ano.17, n. 01, p. 47-62, 2004.

, Graça. Letramento literário: por vielas e alamedas. Revista entreideias:

educação, cultura e sociedade, v. 6, n. 5, 2007.

PERALVA, Angelina T. O jovem como modelo cultural. In: SPÓSITO, Marília Pontes. et al (orgs.). Juventude e contemporaneidade. Brasília: UNESCO, MEC, Anped, 2007, p. 13 a 27.

PINHEIRO, Alexandra Santos. O ensino da literatura: a questão do letramento literário. In: GONÇALVES, Adair Vieira; PINHEIRO, Alexandra Santos e LEAL, Rosa Myriam Avellaneda (orgs.). Leitura e escrita na América Latina: teoria e prática de letramento(s) Dourados: Ed. UFGD, 2011.p. 37 a 55.

REGUILLO, Rossana. Las culturas juveniles: um campo de estúdio; breve agenda para la discusión. In: SPÓSITO, Marília Pontes. et al (orgs.). Juventude e contemporaneidade. Brasília: UNESCO, MEC, Anped, 2007, p. 13 a 27.

ROJO, Roxane. Letramento e capacidades de leitura para a cidadania. São Paulo: SEE: CENP, p. 853, 2004. Disponível em:

$<$ http://www.academia.edu/1387699/Letramento_e_capacidades_de_leitura_para_a_cidadania $>$. Acesso em 18 de fev. de 2015. 217.

VELHO, Gilberto. Juventude, projetos e trajetórias na sociedade contemporânea. In: ALMEIDA, Maria Isabel Mendes e EUGÊNIO, Fernanda (orgs.). Culturas Jovens novos mapas do afeto. Rio de Janeiro: Jorge Zahar, 2006. p. 192 a 201.

VELOSO, Rui. Rui Marques. Não-receita para escolher um bom livro. Casa da leitura, p. 1-11, 2003. Disponível em: 
$<195.23 .38 .178 /$ casadaleitura/portalbeta/bo/abz_indices/000721_NR.pdf $>$. Acesso em 15 de dez de 2014. 218.

VIANA, Maria Luiza. Estéticas, experiências e saberes: artes, culturas juvenis e o ensino médio. In: Juventude e o Ensino Médio. Belo Horizonte: Editora UFMG, 2014, p. 249-268. 